\title{
Parlasul, um novo ator no processo decisório do Mercosul?
}

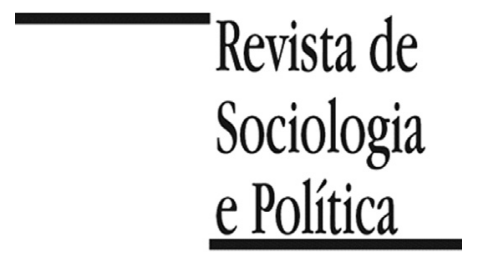

DOI 10.1590/1678-987316245703

\author{
Clarissa Franzoi Dri e Maria Eduarda Paiva
}

\begin{abstract}
Resumo
O Parlamento do Mercosul (Parlasul) enfrenta limitações legais para participar do processo decisório regional. Suas atribuições são restritas e incluem, por exemplo, o envio de projetos de norma e recomendações aos órgãos superiores. Este artigo analisa se e de que maneira o Parlasul se utiliza dessas competências para influenciar as decisões do bloco. Considera-se que o Parlasul dispõe de alguns mecanismos formais e informais que, mesmo limitados, Ihe permitiriam intervir nos temas discutidos pelos órgãos decisórios. Para avaliar se há um poder de agenda parlamentar no Mercosul e se ele é eficaz, procede-se a uma análise quali-quantitativa das recomendações enviadas pelo Parlasul ao Conselho Mercado Comum (CMC). Após estabelecer uma tipologia das recomendações enviadas ao CMC pelo Parlasul entre 2007 e 2010, avalia-se a taxa de resposta do CMC (quantitativamente) e as manifestações do CMC sobre as posições do Parlasul (qualitativamente). Também se compara as agendas do Parlasul e do CMC para identificar eventual superposição ou coincidência de temas. As conclusões apontam para uma desconsideração sistemática das iniciativas parlamentares que visa evitar a quebra do monopólio dos poderes executivos na cena regional. O CMC apenas "toma nota" da maioria das recomendações enviadas pelo Parlasul e aprovou menos de 5\% delas. As agendas de ambos os órgãos são bastante distintas, o que mostra que os assuntos discutidos pelo Parlasul em geral não se tornam regras adotadas pelo Mercosul. Os resultados confirmam a baixa influência de atores outros que os poderes executivos no processo decisório do Mercosul. O artigo ressalta quais mecanismos têm sido usados para evitar que os atores legislativos sejam considerados nas decisões regionais. Caso os parlamentares estejam conscientes deles, eles podem pressionar os órgãos executivos por melhores respostas às recomendações, o que poderia engendrar um papel diferente para os congressos em questões de política externa.
\end{abstract}

PALAVRAS-CHAVE: Mercosul, Poder Legislativo, Ponctuated Equilibrium Theory, agenda, democracia regional.

Recebido em 2 de Maio de 2014. Aceito em 14 de Agosto de 2014.

\section{Introdução ${ }^{1}$}

\author{
1 Agradecemos aos \\ pareceristas anônimos da \\ Revista de Sociologia e \\ Política por seus comentários.
}

$\mathrm{D}$ esde 2007, o Mercosul conta com um parlamento em funcionamento. Sua composição representa as populações dos Estados membros e os documentos oficiais prevêem a eleição direta para seus membros. Cinco anos após sua instalação, cabe questionar em que medida esse novo órgão afetou a dinâmica de trabalho no bloco. Em termos institucionais e políticos, o que mudou após a criação do Parlamento do Mercosul (Parlasul)? Este artigo pretende avaliar o impacto do Parlasul na formulação da agenda do bloco. Se, por um lado, o Parlasul é desprovido de poderes decisórios, por outro, seu poder de deliberação permite-lhe inserir temas nas discussões regionais. Além disso, o Parlasul dispõe de algumas funções legislativas e de controle que, se implementadas, demandariam uma reação por parte dos órgãos executivos, podendo mudar o curso das agendas pré-estabelecidas nacionalmente.

De fato, embora sejam desprovidas de caráter vinculante, as funções do Parlasul encerram um importante potencial de atuação política para a instituição. Se integralmente exploradas pelos parlamentares, essas ações, mesmo não sendo expressa ou imediatamente executadas pelos órgãos decisórios, poderiam gerar debate social, criar constrangimentos entre os atores responsáveis e assim engendrar manifestações por parte dos órgãos decisórios. A pressão política derivada do uso das funções poderia, assim, dar início a uma série de atos 
capazes de modificar o curso de uma política regional. Este trabalho visa justamente apresentar uma avaliação do uso das funções parlamentares que, indo além de possíveis especulações, contribua para um diagnóstico fundamentado dos motivos da dificuldade de consolidação institucional do Parlasul.

Teoricamente, o trabalho fundamenta-se na Punctuated Equilibrium Theory (teoria do equilíbrio interrompido ou pontuado), que oferece um modelo baseado em critérios temporais para explicar o processo de elaboração da agenda pública. Os períodos de estabilidade e ruptura temática que se sucedem nas democracias contemporâneas estariam ligados a monopólios políticos, conforme será explicado na seção II. Esse modelo auxiliará a verificar se e em que medida os parlamentares vêm ameaçando a estabilidade da agenda decisório do bloco. Ademais, a teoria pode indicar estratégias para aumentar o peso do parlamento no embate institucional com os órgãos decisórios.

Na seção III, o artigo abordará a estrutura institucional do Parlasul e os instrumentos legislativos à disposição dos parlamentares. Também se traçará uma tipologia das recomendações enviadas pelo Parlasul ao CMC entre 2007 e 2010, identificando os destinatários, a possibilidade de aplicação imediata e a abrangência geográfica dos atos. Na seção IV, o objetivo é avaliar, quantitativamente, a taxa de resposta do $\mathrm{CMC}$ às recomendações apresentadas pelo Parlasul e identificar, qualitativamente, quais foram objeto de uma manifestação por parte do órgão. Na mesma seção, procede-se a uma comparação entre as agendas do Parlasul e do CMC, a fim de identificar quais assuntos são predominantes nas reuniões de cada órgão e se há uma coincidência entre as agendas.

Essa análise é complementada com entrevistas semiestruturadas realizadas com assistentes de parlamentares do Parlasul, funcionários dos congressos nacionais alocados em funções relativas ao Mercosul e parlamentares. As entrevistas foram realizadas presencialmente em Brasília, Montevideo e Buenos Aires a partir de um questionário prévio a respeito das funções políticas e legislativas do Parlasul. Embora não constituam o foco central da análise aqui apresentada, as entrevistas complementam os dados sobre as normas aprovadas pelo Parlasul e confirmam os resultados a respeito do papel marginal do Parlasul nas diretrizes do bloco. As conclusões buscam explorar os vínculos entre o quadro explicativo teórico e as inferências empíricas, apontando caminhos para a evolução institucional do Parlasul.

\section{A Teoria do equilíbrio interrompido e as agendas regionais}

Esta sessão propõe um quadro teórico para a análise do embate institucional intra-Mercosul com base nos estudos sobre a elaboração das políticas públicas, considerando o objetivo central de verificar o peso do Parlasul por meio da sua influência nas políticas regionais. Trata-se de investigar os mecanismos pelos quais os problemas sociais surgem no cenário político, a maneira pela qual as instituições governamentais formulam alternativas para lidar com eles e o modo pelo qual as soluções são selecionadas, implementadas, avaliadas e revistas. A complexidade e a multiplicidade dos elementos envolvidos nesse processo deram origem, desde os anos 1950, a uma série de teorias explicativas, desde a análise sequencial até os atuais modelos da coalizão militante e do equilíbrio interrompido, passando por diversas concepções racionalistas, institucionalistas e construtivistas ${ }^{2}$.

2 Para um rápido panorama das teorias, veja Sabatier (1999).

A partir dos anos 1980, critérios temporais começaram a ser empregados para compreender o processo de formulação da agenda pública e as razões pelas quais certas políticas são incluídas ou excluídas da agenda. A ação pública passou a ser interpretada não como o produto de uma racionalidade absoluta dos 
atores, mas como um mecanismo fluido e não linear. John Kingdon propôs um modelo baseado na noção de momento, no qual diferentes esferas políticas alinham-se para permitir a emergência de uma nova política. Geralmente, a ascensão de uma ideia não resulta de uma só causa, mas sim de uma combinação de fatores (Kingdon 1984, p.81). Associados em um momento crítico, esses elementos criam oportunidades para mudança. Se um problema é reconhecido, uma solução está disponível e o ambiente político responde positivamente, essa mudança pode tomar grandes proporções.

Antes de mais nada, Kingdon identifica os atores que definem a agenda nos Estados Unidos (idem, pp.21-70). Na esfera do governo, ele diferencia os agentes do Poder Executivo - o presidente, os ministros, os funcionários da presidência e dos ministérios, os assessores pessoais do presidente - dos membros do Poder Legislativo - parlamentares e funcionários do parlamento. O presidente conta com recursos importantes na definição da agenda que podem se converter em um meio de pressão sobre outras instâncias do governo, como prerrogativas constitucionais, unidade organizacional do Executivo e o controle do debate público. Os assessores próximos do presidente trabalham na elaboração de alternativas e outros colaboradores políticos buscam chamar a atenção pública para temas já existentes. Os burocratas, por sua vez, contam com três tipos de recursos para influenciar o andamento das políticas públicas: sua longevidade, seu conhecimento e suas relações com os membros do parlamento ou com os grupos de interesse. O Poder Legislativo também dispõe de uma influência considerável na definição da agenda graças à sua autoridade legal, à publicidade das atividades dos eleitos, à independência e à diversidade das informações recebidas e à longevidade dos funcionários e de alguns parlamentares. A esfera não governamental é composta por grupos de interesse, setor acadêmico, mídia, partidos políticos e opinião pública, que podem influenciar as posições dos formadores da agenda ou constituir redes com membros do governo, criando pontes pelas quais passam as ideias e as orientações técnicas.

Kingdon considera que a arena política está dividida em três esferas (streams), possuindo cada uma um desenvolvimento autônomo segundo uma lógica e um calendário próprios (Ravinet 2004, p.219). Os problemas (problem stream) surgem quando as pessoas estão convencidas de que algo precisa ser feito para modificar uma situação (Kingdon 1984, p.119). Uma simples circunstância pode se tornar um problema quando os indicadores mostram mudanças importantes em seu status, em momentos de crise ou quando uma avaliação revela que uma política não produz os resultados esperados. O autor diferencia a agenda do governo das alternativas para a ação governamental. A agenda é definida como a lista dos assuntos ou problemas que chamam a atenção dos funcionários do governo ou de pessoas externas ao governo que são próximas dos funcionários. As alternativas são soluções concebidas para responder aos problemas que fazem parte da agenda (idem, pp.3-4). As soluções (policy stream) correspondem às propostas que podem se tornar alternativas para os problemas: as chances de que um assunto seja elevado à agenda aumentam quando alternativas viáveis estão disponíveis (idem, p.151). A maior parte das soluções é concebida em comunidades mais ou menos visíveis, compostas por especialistas de um campo do conhecimento, membros do governo ou não. Para gerar um grau suficiente de aceitação, as propostas devem ser alavancadas por empreendedores que facilitam seu caminho em meio à população ou a grupos especializados. Assim, elas devem ser tecnicamente plausíveis, compatíveis com os valores da comunidade e terem potencial para superar certos problemas futuros, como orçamento, consenso entre a classe política etc. A esfera política (political stream) inclui os eventos políticos que podem afetar a agenda, como a opinião pública, a organização das forças políticas (partidos, grupos de pressão), as mudanças na administração ou uma troca de governo (idem, p.152). 
Nesse caso, os acordos são construídos por um processo de barganha, diferentemente da esfera das soluções, onde a persuasão contribui para a construção do consenso entre os especialistas.

Essas três esferas autônomas reúnem-se em períodos críticos formando uma janela de oportunidade, definida como uma ocasião que permite aos atores políticos enfatizarem as soluções consideradas mais apropriadas ou chamarem atenção para problemas considerados importantes (idem, p.173). Trata-se de um fenômeno raro e de curta duração que tem o potencial de produzir uma mudança política relevante. Os problemas ou a cena política podem, por si sós, estruturar a agenda governamental, mas a associação das três esferas é essencial para a inserção de um tema na agenda decisória, que é mais restrita. Essa janela de oportunidade pode ser provocada por uma variação na esfera da vida política ou pelo surgimento de um problema urgente que constrange o governo, obrigando-o a agir. No entanto, a oportunidade não pode ser aproveitada sem a ação dos atores, que encaixam as soluções disponíveis aos problemas políticos quando surge um contexto favorável. A abertura de uma janela de oportunidade aumenta as chances da formação de outra janela para um tema semelhante, visto que a primeira janela estabelece princípios e precedentes que podem provocar efeitos nos campos adjacentes.

O modelo da janela de oportunidade explica melhor a mudança do que a estabilidade na política. Frank Baumgartner e Bryan Jones defendem, no entanto, que o processo de inscrição das políticas públicas na agenda apenas pode ser entendido por meio de uma análise combinada de dois momentos fundamentais: a continuidade e a flutuação (True, Jones \& Baumgartner 1999, p.97). Como Kingdon, que relativiza a regularidade e introduz elementos aleatórios para compreender o mundo político, Baumgartner e Jones (1999) consideram que o percurso das políticas públicas nas democracias ocidentais não é gradual e progressivo, mas episódico e difuso. Contudo, os autores buscam não negligenciar os momentos de estabilidade em benefício dos períodos de variação. Ao contrário, a teoria do equilíbrio interrompido (punctuated equilibrium) associa ambos propondo critérios para determinar momentos estáticos e dinâmicos.

Essa abordagem supõe que longos períodos de estabilidade são interrompidos por curtas ondas de intensa atividade política (idem, p.xvii). Essa lógica está baseada na relação entre o modo como uma política é vista pela população ou pelas elites (policy image) e seu caminho institucional (institutional venue) (Baumgartner \& Jones 1991, pp.1046-1047). As imagens, que incluem informações empíricas e apelos emotivos, contribuem para difundir os temas fora da esfera de influência dos especialistas e dos interesses governamentais, provocando desequilíbrios pontuais no sistema que podem ser compreendidos com a ajuda de noções tais como racionalidade limitada e sentido de urgência. Ademais, uma mudança de governo explica algumas alterações nas políticas, mas não todas: os diferentes órgãos do Estado, onde se incluem os poderes locais, também são vetores importantes de mudança.

A teoria do equilíbrio interrompido considera que os diferentes grupos políticos buscam constantemente estabelecer um monopólio sobre a compreensão de um campo de ação pública, além de um arranjo institucional que reforce esse monopólio (Baumgartner \& Jones 2009, p.6). A instituição serve para organizar o processo de elaboração dessa política e para limitar o acesso de outros grupos. Uma vez que um grupo consegue convencer os outros que seus valores são positivos e que suas propostas podem oferecer soluções para antigos problemas, ele pode conseguir constituir um monopólio. A participação em um monopólio é, então, estruturada por regras formais e informais que desencorajam a participação de pessoas exteriores e também pela aceitação do caráter 
positivo das políticas, suscitando apenas apoio ou indiferença dos não participantes (idem, p.7). A construção de novos monopólios - e a destituição dos antigos - acontece quando há uma mudança na compreensão dos efeitos positivos dos valores defendidos pelos grupos existentes. Durante um conflito pelo monopólio, mesmo um grupo mais fraco pode se sobressair caso sua posição enquadre-se nas concepções majoritárias sobre o que é “positivo". Essa ideia continua válida mesmo considerando-se que uma situação de monopólio ideal é muito difícil de ser mantida e que os diversos subsistemas políticos constituem apenas monopólios incompletos. O monopólio de um campo de ação pública é ainda mais improvável quando há a influência dos partidos políticos. Uma vez organizada segundo as clivagens políticas, uma política é mediatizada e poucas pessoas ficam indiferentes, minimizando as chances de formação de um monopólio (idem, p.22).

Os sistemas políticos não estão jamais em situação de equilíbrio absoluto, mas eles conseguem manter uma estabilidade relativa e duradoura graças à estrutura das instituições políticas e aos acordos sobre as políticas centrais (idem, p.16). As instituições e as ideias se combinam produzindo um sistema de reações negativas (negative feedback) onde dispositivos homeostáticos agem para contrabalançar as forças externas e assim conservar a estabilidade (Baumgartner \& Jones 2002, p.9). A reação negativa é necessária para a proteção dos monopólios políticos. Eles podem, no entanto, ser alterados por um processo contrário que reforça uma tendência externa, no lugar de contrabalança-la (positive feedback). Temporalmente, esse processo se caracteriza por um evento inicial que gera uma cascata de eventos subsequentes, provocando mudanças inesperadas (idem, p. 13).

Dois mecanismos relativos à tomada de decisão podem gerar reações positivas. O primeiro é o efeito mimético: os indivíduos tendem a tomar decisões com base no que outros já decidiram. Essa sensibilidade ao contexto e a tendência à reprodução dos comportamentos podem gerar mecanismos de auto-reforço. O positive feedback pode ser estimulado, em segundo lugar, por uma mudança de foco. No momento de tomar decisões sobre assuntos complexos e multifacetados, é quase impossível aos indivíduos levarem em conta todos os detalhes e níveis de discussão. Assim, eles concentram-se, em geral, em algumas poucas dimensões. Por vezes, eles são obrigados a modificar seu foco devido a uma crise ou a ações de outros atores que tentam impulsionar outras temáticas na agenda. Esse movimento que ressalta novas dimensões de um tema contrabalança os efeitos negativos das características que são habitualmente consideradas, provocando uma reação positiva. Trata-se, no entanto, de um fenômeno raro, visto que na maior parte do tempo os assuntos continuam a ser tratados com a mesma perspectiva e pelos mesmos atores de antes, o que faz da estabilidade uma variável tão importante quanto a mudança (Baumgartner \& Jones 2009, p.256). Ainda mais raramente, a reação positiva ultrapassa a esfera do subsistema e afeta as diferentes ordens de ação do sistema político, o que gera uma dinâmica de ruptura (disruptive dynamics) (idem, p.285). Trata-se de uma mudança na maneira pela qual a informação é recebida e utilizada, o que pode afetar os outros níveis do sistema engendrando modificações na organização partidária ou no poder das elites.

Esse quadro teórico pode auxiliar a compreensão das possibilidades de intervenção do Parlasul no sistema político regional por duas razões centrais. Em primeiro lugar, mesmo tendo sido concebido originalmente para explicar regimes nacionais, a teoria do equilíbrio interrompido, como diversas outras na Ciência Política, auxilia no diagnóstico de fenômenos regionais porque esses demonstram um caráter híbrido, que mistura características domésticas e internacionais. O Mercosul, embora seja uma organização intergovernamental, não pode ser comparada a uma organização internacional clássica quando se trata de 
avaliar seus órgãos e procedimentos políticos. A regularidade, o escopo e o poder decisório de instituições como o GMC, o Focem e o Parlamento fazem com que o sistema político do Mercosul precise ser analisado à luz de ferramentas que combinam perspectivas internacionais e nacionais.

Em segundo lugar, os modos de ação tradicionais do Mercosul vêm sendo progressivamente mais questionados por atores políticos e econômicos e pela imprensa. A falta de efetividade de parcela considerável das decisões regionais e a falta de transparência quanto ao conteúdo das negociações em curso vêm aumentando o grau de insatisfação da população e mesmo das elites com os rumos do bloco. Mesmo assim, os órgãos decisórios não renovam seus métodos e procedimentos e mantêm-se herméticos às demandas políticas e às mudanças geoestratégicas que acontecem na América do Sul principalmente a partir dos anos 2000. A teoria do equilíbrio pontuado favorece o entendimento dos mecanismos de reação negativa que garantem a continuidade das antigas práticas do Mercosul, contrabalançando a força de novas tendências. Mais particularmente, o modelo auxiliará a identificação dos fatores de negative feedback implementados pelo CMC frente ao Parlasul e ao potencial deste último para quebrar as rotinas diplomáticas gerando um sistema de reações positivas. A próxima seção introduzirá a discussão sobre as recomendações do Parlasul aos órgãos decisórios, que são o instrumento formal mais utilizado para influência na agenda pública regional.

\section{O papel das recomendações na produção legislativa do Parlasul}

${ }^{3}$ Para uma descrição mais detalhada da composição, da estrutura organizacional e das funções do Parlasul, ver Dri (2009).
O Parlamento do Mercosul foi criado em 2006 com a finalidade declarada de representar os povos do Mercosul. Em 2007, iniciaram-se as reuniões plenárias mensais em Montevideo. Ele corresponde a uma assembleia unicameral no âmbito do Mercosul e é integrado por representantes designados pelos congressos nacionais até que não sejam realizadas as eleições diretas. A composição, paritária no início, caminha para uma representação proporcional, embora relativa, das populações dos Estados membros. De fato, em seu primeiro ano a assembleia contava com 18 parlamentares de cada um dos países membros (Argentina, Brasil, Paraguai e Uruguai). A partir de 2012, com a aprovação do critério de proporcionalidade, o Parlasul tem 37 representantes brasileiros, 26 argentinos, 18 paraguaios, 18 uruguaios e 23 venezuelanos. Todos os representantes são membros dos congressos nacionais, com exceção do Paraguai, que realizou eleições diretas para o Parlasul em $2008^{3}$.

A assembleia possui funções consultivas de deliberação e controle dos órgãos executivos. Em termos legislativos, o Protocolo Constitutivo do Parlamento do Mercosul e seu Regimento Interno estabelecem que a assembleia conta com os seguintes instrumentos:

- Pareceres: opiniões formais sobre projetos legislativos do CMC. Se as sugestões do Parlamento forem consideradas, o projeto tramita nos congressos nacionais de modo acelerado;

- Projetos de lei: propostas legislativas apresentadas ao CMC;

- Anteprojetos de lei: propostas apresentadas aos parlamentos nacionais visando harmonizar as legislações dos Estados membros;

- Recomendações: propostas de políticas a serem levadas a cabo pelos órgãos decisórios do Mercosul;

- Informes: estudos sobre assuntos específicos elaborados pelas comissões do Parlamento;

- Declarações: manifestações sobre temas de interesse público; 
4 A partir de 2011 o Parlasul entra em uma fase de suspensão das sessões plenárias, pelo que a atividade normativa decai consideravelmente.
- Disposições: regras administrativas sobre a organização interna da instituição.

Esta seção propõe realizar um diagnóstico das recomendações elaboradas pelo Parlasul em termos de destinatários, aplicabilidade e abrangência espacial. Esses atos, juntamente com os projetos de lei e pareceres, são os instrumentos legislativos que mais fortemente vinculam o Parlamento aos órgãos decisórios. Embora as declarações e disposições sejam mais numerosas, elas são mais frágeis em termos de influência política nas relações interinstitucionais. As declarações evidenciam posições da instituição sobre temas variados, que são, em grande parte das vezes, alheios às competências regionais. As disposições, por sua vez, regulam o funcionamento interno da instituição, o que não gera um impacto direto no conteúdo das políticas do Mercosul, Como o Parlasul nunca elaborou pareceres e os projetos de lei são raros (Dri 2009, p.89; Medeiros, Paiva \& Lamenha 2012, p.166), as recomendações oferecem mais subsídio para a análise das agendas buscada neste trabalho. Ao longo dos anos em análise (2007-2013) $)^{4}$ o Parlasul produziu 53 recomendações. Com essa quantidade, esse tipo de ato é o terceiro maior em relação ao total de aprovações, sendo superado apenas pelas disposições e declarações (que contam com 63 atos cada). Os dados demonstram que o principal destinatário das recomendações do Parlasul é o Conselho Mercado Comum. Em realidade, como mostra o Gráfico 1 , o CMC responde por $87 \%$ das recomendações expedidas.

Deve-se considerar, contudo, que, dos 46 atos destinados ao CMC, 23 deles são indiretamente dirigidos aos Estados membros. Em outros termos, o Parlasul muitas vezes requer que o CMC instrua os Estados Partes a agirem de determinada maneira ou assinala uma medida que somente pode ser posta em prática se discutida no plano doméstico. Um exemplo prático é a Recomendação $\mathrm{n}^{\circ}$ 01/08, em que o Parlasul pede ao CMC que estimule os Estados Partes a adotarem políticas que introduzam a Internet em todas as escolas públicas do Mercosul. A recomendação é endereçada ao $\mathrm{CMC}$, mas tem como objetivo influenciar as políticas públicas de cada Estado membro sem que necessariamente seja formulada uma decisão regional.

Com respeito à execução das resoluções propostas pelo Parlasul, constatou-se que, em 58\% dos casos, é possível sua implementação imediata (Gráfico 2). Isso significa que a medida não exige um grande esforço de negociação entre os Estados Partes, uma vez que a negociação já aconteceu em outro âmbito. Assim, o documento enviado pode ser imediatamente aprovado. É o

\section{Gráfico 1 - Órgãos destinatários das recomendações do Parlasul, 2007-2013 - Secretaria do Mercosul $\square$ Grupo Mercado Comum Estados partes n Conselho Mercado Comum}

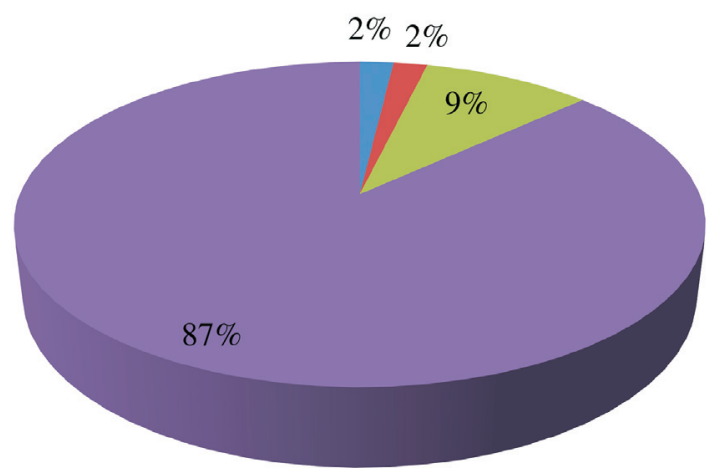

Fonte: As autoras, com base em dados coletados na página eletrônica oficial da Secretaria do Mercosul. 
Gráfico 2 - Aplicabilidade das recomendações aprovadas pelo Parlasul, 2007-2013

- Possível execução imediata Difícil aplicabilidade imediata

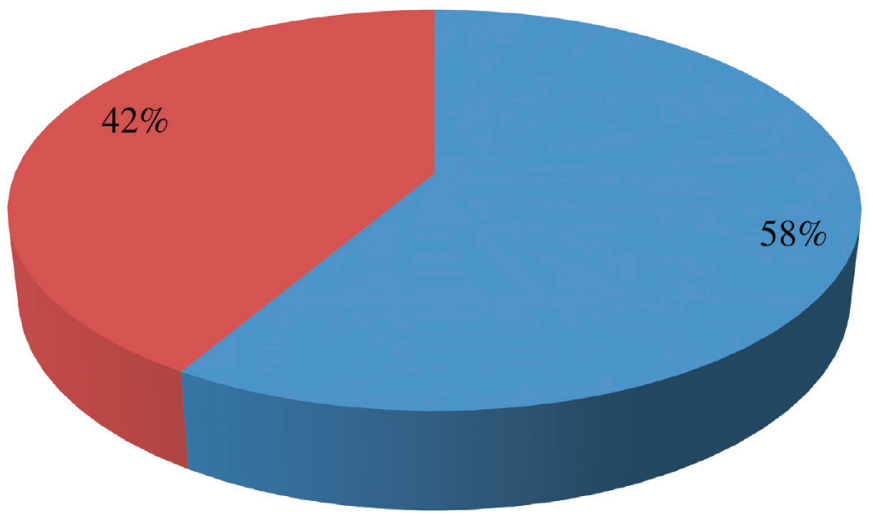

Fonte: As autoras, com base em dados coletados na página eletrônica oficial da Secretaria do Mercosul.

caso da Recomendação ${ }^{\circ}$ 07/08, que sugere a assinatura da Convenção dos Direitos das Pessoas com Deficiência. Ora: não se trata de um tema que engendre grandes polêmicas, e a recomendação somente requer assinatura e ratificação - e não cumprimento - de um documento já discutido na Assembleia Geral das Nações Unidas. Por sua vez, a Recomendação nº 09/2010 pede ao CMC que estabeleça medidas de controle para as atividades de caça, pesca, extração de madeira e introdução de gado em áreas protegidas limítrofes. Como o documento não expressa quais seriam as medidas a serem tomadas, o CMC precisa remeter a questão ao Subgrupo do GMC responsável pela matéria para sua regulamentação. Isso faz com que a recomendação não possa ter uma aplicabilidade imediata.

É necessário ressaltar que a aplicabilidade das medidas não se relaciona diretamente com sua relevância. É possível que haja medidas de difícil aplicabilidade imediata que sejam importantes para a consolidação de um poder de agenda do Parlasul. Na Recomendação n ${ }^{\circ}$ 21/09, por exemplo, o Parlasul requer que se estabeleça rapidamente a compatibilização das regulamentações internas dos Estados Membros sobre tarifas de combustível, cobranças de tributos, dimensões e pesos dos veículos etc. Trata-se de um tema que exige uma harmonização de políticas públicas e que é importante para a integração física. O Parlasul busca, por meio da aprovação da recomendação, inserir-se no debate, mas sua simples aprovação pelo CMC não seria possível, visto que as questões levantadas carecem de regulamentação. Por sua vez, a implementação da Recomendação ${ }^{\circ}$ 05/09, que insta os governos do Paraguai e do Brasil a denominarem a ponte Internacional Rodoferroviária de Ñemoirú seria de fácil aplicação, mas não fortaleceria de forma considerável o poder de agenda do Parlasul.

Uma das fortes críticas ao Parlamento do Mercosul é que sua atividade muitas vezes se limita a questões locais e nacionais. Em outros termos, embora a instituição seja uma instância regional, seus parlamentares discutiriam com mais frequência problemas relativos à sua região ou país de origem. Uma expressão desse problema seria a dificuldade que os parlamentares encontram em formar grupos políticos que superem a dimensão nacional. No entanto, os resultados da análise da abrangência das recomendações apresentam um contraponto a essa concepção. Na verdade, $70 \%$ das recomendações discutem ques- 
${ }^{5}$ Entrevista da autora com uma assessora parlamentar argentina em Buenos Aires, março de 2009. tões de abrangência regional, ou seja, que envolvem todos os Estados membros, como mostra o Gráfico 3. Ainda que se comprove que os demais atos não seguem o mesmo padrão de abrangência, deve-se considerar que as recomendações são um mecanismo hábil de diálogo entre o Parlasul e o CMC. Ademais, mesmo que a origem das propostas seja paroquial, a preocupação dos parlamentares em conferi-las um caráter regional indica um processo de socialização em curso com as temáticas vinculadas à integração. Assim, pode-se afirmar que as medidas propostas ao CMC pelo Parlasul são, mais frequentemente, regionais do que locais - o que em certa medida abranda as críticas sobre o "localismo" do órgão.

Além do enfoque geográfico das recomendações, é preciso também considerar a relevância da produção normativa. Tomando o Parlamento Europeu (PE) como exemplo, observou-se que, mesmo quando os parlamentares dispunham de poucas competências, o PE não se furtava em utilizar seu poder de deliberação para sugerir reformas nos tratados e, com isso, tentar influenciar a produção normativa (Costa \& Saint Martin 2009, p.62). Essa estratégia reivindicatória surtiu efeitos ao longo do tempo e o PE tornou-se instituição importante no processo decisório. No caso do Parlasul, a instituição insiste em produzir recomendações que não reivindicam novos poderes. Em realidade, $32 \%$ das recomendações produzidas tratam de questões de pouca repercussão para o projeto de integração regional, tais como designação de datas comemorativas ou pedido de informação. Sobre o tema, uma assessora parlamentar afirmou:

"Se você observa os projetos [dos parlamentares do Parlasul], são todos de, por exemplo, 'façamos um monumento a Che Guevara', 'façamos um monumento a José Martí', sem impacto político, ou em um nível declaratório [...]. Projetos mais elaborados até que isso não se resolva, e até que o tema dos critérios de representação não se resolva, o Parlasul vai ter um papel secundário." 5

A análise das recomendações produzidas pelo Parlasul estaria incompleta sem que se discutisse o papel cumprido pelo principal destinatário desses atos. Visto que o Parlasul é um órgão consultivo no organograma institucional do Mercosul, sua produção normativa precisa ser considerada pelos órgãos decisórios do bloco. Por essa razão, a seção seguinte discute se e como as recomendações do parlamento regional são recebidas pelo CMC, além de promover uma

Gráfico 3 - Abrangência espacial das recomendações aprovadas pelo Parlasul, 20072013

\section{Local $\square$ Regional Binacional}

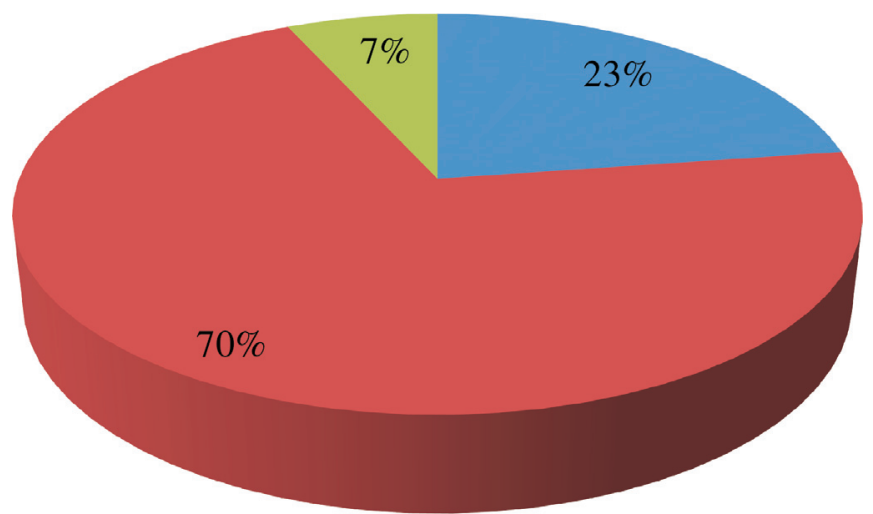

Fonte: As autoras, com base em dados coletados na página eletrônica oficial da Secretaria do Mercosul. 
comparação temática entre as agendas de ambas as instituições. O objetivo é verificar o grau de influência formal ou informal dos atores parlamentares sobre o processo de elaboração da agenda do órgão máximo do bloco.

\section{Parlasul versus CMC: agendas assimétricas e interação deficitária}

${ }^{6}$ Sistematização das autoras com base em dados coletados na página oficial da Secretaria do Mercosul.

\footnotetext{
${ }^{7}$ Ata da XLII Reunião Ordinária do CMC, p. 3.
}

Mesmo que as recomendações do Parlasul sejam encaminhadas aos órgãos decisórios, não há garantia de que elas de fato sejam apreciadas. Ainda assim, com respeito às recomendações enviadas ao CMC entre 2007 e 2010, 93\% delas são pelo menos mencionadas nas reuniões do órgão ${ }^{6}$. Isso não significa, no entanto, que elas sejam de fato debatidas e aprovadas. De um total de 46 recomendações mencionadas nas reuniões, apenas uma foi aprovada ao longo do quadriênio em exame. Outra recomendação, datada de 2010, logrou aprovação na reunião de julho de 2011. Como previsto na hipótese inicial, o procedimento mais comumente adotado pelo CMC é o de "tomar nota" das recomendações e declarações emanadas do Parlasul, sem que haja uma indicação precisa quanto ao alcance dessa ação.

Os números apontam a frequência com que esse procedimento é adotado: em $67 \%$ dos casos, o CMC optou por tomar nota da recomendação, sem indicar se haveria discussões posteriores. Em realidade, mesmo quando a resposta do CMC destoa da ação de "tomar nota", como é o caso do envio do documento a outro órgão regional, não se observa o retorno do ato ao CMC, o que demonstra que a discussão não é prioritária. A Tabela 1 aponta o tempo de resposta do $\mathrm{CMC}$ aos atos produzidos pelos Parlasul que foram mencionados nas reuniões do órgão decisório, além de explicitar como as questões suscitadas foram tratadas.

Em geral, as atas do CMC não mencionam os atos do Parlasul individualmente, mas sim em bloco. Tome-se como exemplo a XLII Reunião Ordinária do CMC, de cuja ata se extraiu o seguinte excerto:

“O CMC tomou nota das Recomendações n01/11 'Solução pacífica para o problema das Ilhas Malvinas' e das Declarações n01/11 'Apoio ao Estabelecimento de uma Assembleia Parlamentar das Nações Unidas' e 02/11 'Rechaço às expressões do presidente Nicolás Sarkozy', adotadas em dito âmbito.”7

Percebe-se que os temas supramencionados não são correlatos. Na verdade, o seu agrupamento na ata é possível porque não há debate sobre as questões propostas. Ao registrar alguns dos atos do Parlasul em ata, o CMC formalmente considera a atuação da instituição no âmbito regional. Entretanto, na prática, essas anotações não se relacionam com a agenda política do CMC. Observa-se que o principal critério para a inclusão dos atos anotados não é o temático, mas o temporal. Na grande maioria dos casos, o CMC inclui em sua pauta os atos aprovados nas reuniões do Parlasul imediatamente anteriores. No caso das Declarações $n^{\circ} 1$ e 2 de 2007 , essa práxis significou um intervalo de apenas três dias entre a aprovação dos atos e a tomada de nota na reunião do CMC - o que significa que dificilmente as questões ventiladas foram analisadas com profundidade antes da reunião do órgão decisório. Por haver mais encontros do Parlasul que do CMC ao longo do ano, o órgão decisório frequentemente tem de incluir em sua pauta atos aprovados em diversas reuniões do Parlasul. Ainda assim, a lógica se mantém: trata-se de atos aprovados no intervalo entre duas reuniões do CMC.

Essa constatação empírica comporta exceções bastante significativas. Nos casos em que não houve tão-somente uma tomada de nota, mas sim a efetiva aprovação do ato, o CMC não respeita a lógica temporal supramencionada. É o caso da Recomendação ${ }^{\circ} 16 / 10$ que, apesar de ter sido aprovada a tempo de ser incluída na reunião de 16 de dezembro de 2010, somente foi aprovada em 28 de 
Tabela 1 - Tempo de resposta do CMC aos atos normativos do Parlasul, 2007-2013*

\begin{tabular}{|c|c|c|c|c|}
\hline Ato & $\begin{array}{l}\text { Aprovação no } \\
\text { Parlasul }\end{array}$ & $\begin{array}{c}\text { Consideração no } \\
\text { CMC }\end{array}$ & Ação & Intervalo de tempo \\
\hline Declaração n ${ }^{\circ}$ 01/2007 & $25 / 06 / 2007$ & 28/06/2007 & Tomou nota & 3 dias \\
\hline Declaração no 02/2007 & $25 / 06 / 2007$ & $28 / 06 / 2007$ & Tomou nota & 3 dias \\
\hline Recomendação n 01/07 & 03/09/2007 & $17 / 12 / 2007$ & Tomou nota & $3 \mathrm{me} 3 \mathrm{~d}$ \\
\hline Declaração n ${ }^{\circ} 10 / 08$ & $27 / 06 / 2008$ & $30 / 06 / 20078$ & Destacou & $3 \mathrm{~d}$ \\
\hline Recomendação ${ }^{\circ}$ 02/08 & $28 / 07 / 2008$ & $15 / 12 / 2008$ & Remeteu ao GMC & $4 \mathrm{me} 18 \mathrm{~d}$ \\
\hline Recomendações n ${ }^{\circ}$ 3/08 e 4/08 & $15 / 09 / 2008$ & $15 / 12 / 2008$ & Tomou nota & $3 \mathrm{~m}$ \\
\hline Recomendação $n^{\circ}$ 5/08 & 03/11/2008 & $15 / 12 / 2008$ & Remeteu à RME & $1 \mathrm{~m} \mathrm{e} 12 \mathrm{~d}$ \\
\hline Recomendação ${ }^{\circ}$ 6/08 & 03/11/2008 & $15 / 12 / 2008$ & Tomou nota & $1 \mathrm{~m} \mathrm{e} 12 \mathrm{~d}$ \\
\hline Recomendação n $7 / 08$ & $03 / 11 / 2008$ & $15 / 12 / 2008$ & $\begin{array}{l}\text { Remeteu à } \\
\text { RAADDHH }\end{array}$ & $1 \mathrm{~m} \mathrm{e} 12 \mathrm{~d}$ \\
\hline Recomendação $n^{\circ}$ 8/08 & 03/11/2008 & $15 / 12 / 2008$ & Remeteu à RMS & $1 \mathrm{~m} \mathrm{e} 12 \mathrm{~d}$ \\
\hline Recomendação n ${ }^{\circ}$ 9/08 a 10/08 & 03/11/2008 & $15 / 12 / 2008$ & Tomou nota & $1 \mathrm{me} 12 \mathrm{~d}$ \\
\hline Recomendação n ${ }^{\circ} 11 / 08$ & $28 / 11 / 2008$ & $15 / 12 / 2008$ & Tomou nota & $17 \mathrm{~d}$ \\
\hline Recomendações $n^{\circ} 1 / 09$ a 3/09 & $28 / 04 / 2009$ & 23/07/2009 & Tomou nota & $2 \mathrm{me} 17 \mathrm{~d}$ \\
\hline Recomendações n 4/09 a 11/09 & $18 / 05 / 2009$ & 23/07/2009 & Tomou nota & $2 \mathrm{~m}$ e $05 \mathrm{~d}$ \\
\hline Declaração $n^{\circ} 1$ & $16 / 03 / 2009$ & 23/07/2009 & Tomou nota & $4 \mathrm{~m} \mathrm{e} 07 \mathrm{~d}$ \\
\hline Declarações n ${ }^{\circ} 2$ a 4 & $28 / 04 / 2009$ & 23/07/2009 & Tomou nota & $2 \mathrm{~m}$ e $25 \mathrm{~d}$ \\
\hline Declarações $n^{\circ} 5$ a 6 & $18 / 05 / 2009$ & 23/07/2009 & Tomou nota & $2 \mathrm{~m}$ e $05 \mathrm{~d}$ \\
\hline Anteprojeto de norma $\mathrm{n}^{\circ} 1$ & $28 / 04 / 2009$ & $23 / 07 / 2009$ & Tomou nota & $2 \mathrm{~m}$ e $25 \mathrm{~d}$ \\
\hline Recomendação nº 1/2009 & $28 / 04 / 2009$ & $07 / 12 / 2009$ & Remeteu ao FCCP & $7 \mathrm{~m} 9 \mathrm{~d}$ \\
\hline Recomendação nº 2/2009 & $28 / 04 / 2009$ & 07/12/2009 & Remeteu ao FCCP & $7 \mathrm{~m} 9 \mathrm{~d}$ \\
\hline $\begin{array}{l}\text { Proposta n }{ }^{\circ} \text { AE/VI SO/2007/nº } 47 \\
\text { (critério de representação) }\end{array}$ & $28 / 04 / 2009$ & $18 / 10 / 2010$ & Aprovou & $1 \mathrm{a}, 5 \mathrm{~m}$ e $20 \mathrm{~d}$ \\
\hline $\begin{array}{l}\text { Recomendações } n^{\circ} 01 / 10 \text { a 02/10 e } \\
\text { Projetos de Normas n }{ }^{\circ} 01 \text { e 02/10 }\end{array}$ & 08/03/2010 & $16 / 12 / 2010$ & Tomou nota & $9 \mathrm{me} 8 \mathrm{~d}$ \\
\hline Recomendações $n^{\circ}$ 03/10 a 07/10 & $10 / 05 / 2010$ & $16 / 12 / 2010$ & Tomou nota & $7 \mathrm{me} 6 \mathrm{~d}$ \\
\hline Recomendações $n^{\circ}$ 08/10 a 11/10 & 07/06/2’010 & $16 / 12 / 2010$ & Tomou nota & $6 \mathrm{~m} \mathrm{e} 9 \mathrm{~d}$ \\
\hline Recomendação n $16 / 2010$ & $13 / 12 / 2010$ & $28 / 06 / 2011$ & Aprovou & $6 \mathrm{~m} 15 \mathrm{~d}$ \\
\hline Recomendação n¹/2011 & Sem informação & $19 / 12 / 2011$ & Tomou nota & - \\
\hline Declarações $n^{\circ} 01 / 11$ e $02 / 11$ & Sem informação & $19 / 12 / 2011$ & - & - \\
\hline
\end{tabular}

*Para fins de informação, incluem-se nessa tabela todos os atos do Parlasul que obtiveram resposta por parte do CMC, não apenas as recomendações.

Legendas: a: anos; m: meses; d: dias; RMS: reunião de ministros da saúde; RAADDHH: Reunião de Altas Autoridades em Direitos Humanos do MERCOSUL; GMC: Grupo Mercado Comum; RME: Reunião de Ministros da Educação; FCCP: Foro de Consulta e Concertação Política.

Fonte: As autoras, com base em dados coletados na página eletrônica oficial da Secretaria do Mercosul.

julho de 2011. Isso também ocorreu com a Proposta n ${ }^{\circ}$ AE/VI SO/2007/N 47 , relativa ao critério de representação cidadã, que demorou quase um ano e meio para ser aprovada. Observa-se, então, que o imediatismo na inclusão de um ato na pauta não necessariamente significa que ele será efetivamente analisado. $\mathrm{Na}$ verdade, há fortes indícios de que a aprovação segue um rito oposto, de atraso na discussão e aprovação. Isso levaria a pensar que quanto maior a rapidez de inclusão do ato do Parlasul na agenda do CMC, menor a probabilidade de que o CMC tome medidas para o cumprimento da demanda dos parlamentares. De toda sorte, dado o baixo índice de aprovação e discussão pelo CMC dos atos do 
8 Entrevista com um funcionário do Parlamento do Mercosul, Montevidéu, março de 2009.
Parlasul, conclui-se que o parlamento pouco influencia na agenda do órgão decisório por meio de mecanismos formais.

Uma decisão específica faz com que se considere que mecanismos informais influenciam na agenda do CMC. Trata-se da norma que constitui o Grupo de Alto Nível sobre Relação Institucional entre o Conselho Mercado Comum e o Parlamento do Mercosul, o Ganrel, que tem por objetivo elaborar uma proposta relativa aos procedimentos de interação entre os dois órgãos (Mercosul/CMC/DEC, $n^{\circ}$ 47/08). Embora a criação desse grupo fosse de interesse do Parlasul, o parlamento não enviou ao órgão decisório qualquer ato que propusesse a criação do Ganrel. Aparentemente, trata-se então de uma iniciativa que partiu do CMC. Entretanto, o órgão decisório não teria, em princípio, razões para incentivar a formação do grupo, já que ele poderia oferecer melhores instrumentos ao Parlasul para participar de um processo decisório controlado pelos Executivos nacionais. Assim, pode ter havido uma pressão informal, não captada pela análise da agenda de ambos os órgãos, para a criação de uma instituição que pode vir a beneficiar o Parlasul. Portanto, ainda que o Parlamento não consiga garantir a aprovação de suas recomendações no CMC, ele poderia influenciar indiretamente os temas discutidos nas reuniões do órgão decisório. Essa ideia também é corroborada pelas entrevistas realizadas:

"Queira ou não, às vezes a gente não tem uma recomendação formal ao Conselho sobre determinado tema, mas se [um deputado] na reunião do CMC chega no ouvido do [ministro de relações exteriores], dá pra resolver as coisas e dá pra sair um parágrafo na declaração de presidentes. Muitas coisas se resolvem assim."

Para verificar o poder de agenda informal, compararam-se as agendas do Parlasul e do CMC. Na análise da agenda do Parlasul, procedeu-se à classificação das recomendações de acordo com os temas das comissões parlamentares. Isso não significa necessariamente que os atos foram oriundos dessas comissões (a origem da proposta não está especificada no documento), mas sim que o tema da recomendação enquadra-se nas competências da comissão. Somente foram considerados os atos aprovados em plenário, e não a totalidade das propostas discutidas. Quanto aos assuntos mais abordados no Parlasul, há uma relativa distribuição temática. A maioria das recomendações está relacionada a Desenvolvimento regional sustentável, ordenamento territorial, habitação, saúde, meio ambiente e turismo, seguida por Infraestrutura, transportes, recursos energéticos e agricultura, pecuária e pesca. Observa-se a pouca aprovação de resoluções que discutem assuntos econômicos, financeiros e comerciais, questão de fundamental importância em um modelo de integração liberal. Ao praticamente ignorar a temática econômica, o Parlasul deixa de tentar influenciar em uma questão sensível do bloco. Pode-se argumentar que o Mercosul possui órgãos executivos especializados na regulação econômica e comercial, e por isso o Parlasul poderia se manter alheio a elas. No entanto, o escrutínio e o debate pelos parlamentos de todos os assuntos de interesse da sociedade constituem bases da democracia contemporânea. A Tabela 2 analisa as aprovações de recomendações de acordo com o assunto.

Com relação ao CMC, analisou-se a produção normativa do mesmo período, com base nas atas das reuniões semestrais. Para fins comparativos, a classificação também obedeceu ao critério temático das comissões do Parlasul. No que tange à distribuição das decisões por assunto, verifica-se uma grande quantidade de atos que versam sobre organização interna no órgão (Orçamento e Assuntos Internos) e sobre Assuntos econômicos, financeiros, comerciais, fiscais e monetários. Este último representa apenas 3,77\% das recomendações do Parlasul, o que permite concluir que a estrutura parlamentar não busca ativamente influenciar esse âmbito da integração (Tabela 3 e Tabela 4). Por sua vez, o tema do Desenvolvimento Regional Sustentável, Ordenamento Territo- 
Tabela 2 - Classificação temática das recomendações do Parlasul, 2007-2010

\begin{tabular}{|c|c|c|c|c|c|c|}
\hline Tema & 2007 & 2008 & 2009 & 2010 & Soma & $\%$ \\
\hline Assuntos Jurídicos e Institucionais & 2 & 1 & 4 & 2 & 9 & 16,98 \\
\hline Assuntos Econômicos, Financeiros, Comerciais, Fiscais e Monetários & 0 & 2 & 0 & 0 & 2 & 3,77 \\
\hline Educação, Cultura, Ciência, Tecnologia e Esportes & 0 & 1 & 7 & 0 & 8 & 15,09 \\
\hline Trabalho, Políticas de Emprego, Seguridade Social e Economia Social & 0 & 0 & 1 & 1 & 2 & 3,77 \\
\hline $\begin{array}{l}\text { Desenvolvimento Regional Sustentável, Ordenamento Territorial, Ha- } \\
\text { bitação, Saúde, Meio Ambiente e Turismo }\end{array}$ & 1 & 2 & 2 & 10 & 15 & 28 \\
\hline Cidadania e Direitos Humanos & 0 & 2 & 4 & 1 & 7 & 13,20 \\
\hline $\begin{array}{l}\text { Infra-Estrutura, Transportes, Recursos Energéticos e Agricultura, Pe- } \\
\text { cuária e Pesca }\end{array}$ & 0 & 2 & 5 & 2 & 09 & 16,98 \\
\hline Orçamento e Assuntos Internos & 0 & 1 & 0 & 0 & 1 & 1,88 \\
\hline Soma & 3 & 11 & 25 & 15 & 53 & \\
\hline
\end{tabular}

Fonte: As autoras, com base em dados coletados na página eletrônica oficial da Secretaria do Mercosul.

Tabela 3 - Classificação temática das decisões do CMC, 2007-2010

\begin{tabular}{|c|c|c|c|c|c|c|}
\hline Tema & 2007 & 2008 & 2009 & 2010 & Soma & $\%$ \\
\hline Assuntos Econômicos, Financeiros, Comerciais, Fiscais e Monetários & 12 & 11 & 10 & 20 & 53 & 25,85 \\
\hline Educação, Cultura, Ciência, Tecnologia e Esportes & 3 & 9 & 4 & 3 & 19 & 9,26 \\
\hline Trabalho, Políticas de Emprego, Seguridade Social e Economia Social & 2 & 5 & - & - & 7 & 3,41 \\
\hline $\begin{array}{l}\text { Desenvolvimento Regional Sustentável, Ordenamento Territorial, Ha- } \\
\text { bitação, Saúde, Meio Ambiente e Turismo }\end{array}$ & 1 & 1 & 4 & - & 6 & 2,92 \\
\hline Cidadania e Direitos Humanos & 3 & 6 & 2 & 5 & 16 & 7,80 \\
\hline $\begin{array}{l}\text { Infra-Estrutura, Transportes, Recursos Energéticos e Agricultura, Pe- } \\
\text { cuária e Pesca }\end{array}$ & 8 & 6 & 2 & 11 & 27 & 13,17 \\
\hline Orçamento e Assuntos Internos & 26 & 15 & 10 & 18 & 69 & 33,65 \\
\hline Soma & 55 & 56 & 32 & 62 & 205 & \\
\hline
\end{tabular}

Fonte: As autoras, com base em dados coletados na página eletrônica oficial da Secretaria do Mercosul.

rial, Habitação, Saúde, Meio Ambiente e Turismo, bastante priorizado pelo Parlasul, corresponde apenas a 2,92\% das normas aprovadas no CMC.

Cabe discutir as matérias de Educação, Cultura, Ciência, Tecnologia e Esportes e Infraestrutura, Transportes, Recursos Energéticos e Agricultura, Pecuária e Pesca, cuja aprovação de atos é considerável tanto no CMC quanto no Parlasul (Tabela 4). Da análise das recomendações e decisões em questão, conclui-se que apenas uma matéria levantada no Parlasul foi efetivamente considerada pelo CMC: a adoção do guarani como idioma oficial. Ainda assim, a ação adotada pelo órgão decisório foi a remissão da recomendação ao FCCP, e não houve decisão sobre o tema. A falta de compatibilidade entre as agendas indica a ausência de uma influência, mesmo que no nível informal, do Parlasul sobre o CMC. Em geral, não há coincidência entre os temas abordados em ambos os órgãos, sendo que a única obedeceu a mecanismos formais já analisados. A falta de tratamento no Parlasul de temas considerados centrais por outras instituições é referência no discurso dos atores:

"Então é por isso que eu digo: se você pega o Parlamento do Mercosul hoje, da forma como ele tá, e levar pra dentro dele, rapidamente, os problemas dos quatro países e dentro do Parlamento ajudar a resolver, nós teremos um Parlamento 
Tabela 4 - Classificação temática comparativa CMC-Parlasul, em porcentagem, 20072010

\begin{tabular}{lcc}
\hline Tema & Parlasul & CMC \\
\hline Assuntos Jurídicos e Institucionais & 16,98 & 3,90 \\
Assuntos Econômicos, Financeiros, Comerciais, Fiscais & 3,77 & 25,85 \\
e Monetários & 15,09 & 9,26 \\
Educação, Cultura, Ciência, Tecnologia e Esportes & 3,77 & 3,41 \\
Trabalho, Políticas de Emprego, Seguridade Social e & & \\
Economia Social & 28 & 2,92 \\
$\begin{array}{l}\text { Desenvolvimento Regional Sustentável, Ordenamento } \\
\text { Territorial, Habitação, Saúde, Meio Ambiente e Turismo }\end{array}$ & 13,20 & 7,80 \\
Cidadania e Direitos Humanos & 16,98 & 13,17 \\
Infra-Estrutura, Transportes, Recursos Energéticos e & & \\
Agricultura, Pecuária e Pesca & 1,88 & 33,65 \\
Orçamento e Assuntos Internos & & \\
\hline
\end{tabular}

Fonte: As autoras, com base em dados coletados na página eletrônica oficial da Secretaria do Mercosul.

9 Entrevista com um assessor parlamentar brasileiro em Brasília, abril de 2009. fantástico. Se nós pegarmos o Parlamento do Mercosul e ficarmos brigando, de picuinha pra lá e pra cá, não teremos absolutamente nada."”.

Esse hiato entre as agendas não contribui para a formação de um momento oportuno para o aumento da influência política do Parlasul. Segundo o modelo proposto por Kingdon (1984), para que ocorra uma mudança institucional significativa é preciso que a esfera dos problemas, das soluções e da arena política estejam alinhadas. Nesse caso, nem os problemas selecionados por parlamentares e atores executivos são coincidentes, nem estes parecem satisfeitos com as soluções apontadas pelos parlamentares. Assim, não se pode falar na formação de uma janela de oportunidade para o incremento da atuação parlamentar. Da mesma forma, sem poder de agenda os parlamentares não conseguem constituir um grupo que se sobreponha à ação dos atores executivos. Esse fenômeno poderia gerar uma dinâmica de reações positivas que contrabalançassem o papel dos valores dominantes (Baumgartner \& Jones 2009), evento que poderia modificar substancialmente o equilíbrio de forças no Mercosul e potencialmente regionalizar as decisões, ainda muito concentradas no âmbito nacional por meio das diplomacias.

Do problema específico do Parlasul, a saber, a dificuldade em influenciar a agenda do CMC, surge um mais geral: afinal, quais são os órgãos do Mercosul dotados de um forte poder de agenda? A partir dessa questão, analisou-se a aprovação de decisões no CMC entre os anos de 2007 e 2010, tendo como foco o órgão em que se originou o ato normativo (Tabela 5).

Conforme apresenta a Tabela 5, o Grupo Mercado Comum (GMC) é responsável pela elaboração da maioria das decisões, seguido do próprio CMC. Os dois outros órgãos responsáveis por um número expressivo de aprovações são o Fundo para a Convergência Estrutural do Mercosul (Focem) e o Foro de Consulta e Concertação Política (FCCP). Os demais órgãos obtiveram pouco espaço na agenda do CMC, contando, em média, com três atos aprovados. Uma breve análise da composição dos órgãos supramencionados demonstra que a agenda discutida é praticamente monopolizada pelos poderes executivos. De acordo com o art. 4 do Protocolo de Ouro Preto (POP), o CMC é formado pelos Ministros das Relações Exteriores e da Economia dos Estados Partes. Composição semelhante é a do GMC (art. 11, POP), formado por membros designados 
Tabela 5 - Origem dos atos aprovados no CMC, 2007-2010

\begin{tabular}{|c|c|c|c|c|}
\hline Órgão & Sigla & $\begin{array}{c}\text { Número } \\
\text { de atos }\end{array}$ & $\begin{array}{l}\text { Porcentagem em } \\
\text { relação ao total }\end{array}$ & Observações \\
\hline Reunião de Ministros de Meio Ambiente & RMMA & 01 & $0,45 \%$ & - \\
\hline Comitê Mercosul Livre de Febre Aftosa & CMA & 01 & $0,45 \%$ & - \\
\hline Reunião de Ministros de Cultura & RMC & 01 & $0,45 \%$ & - \\
\hline Subgrupo de trabalho $\mathrm{n}^{\circ} 2$ & SGT2 & 3 & $1,35 \%$ & - \\
\hline Subgrupo de trabalho $\mathrm{n}^{\circ} 5$ & SGT5 & 2 & $0,90 \%$ & - \\
\hline Subgrupo de trabalho $\mathrm{n}^{\circ} 6$ & SGT6 & 1 & $0,45 \%$ & - \\
\hline Subgrupo de trabalho $n^{\circ} 4$ & SGT4 & 1 & $0,45 \%$ & - \\
\hline Conselho Mercado Comum & $\mathrm{CMC}$ & 50 & $22,62 \%$ & - \\
\hline Grupo Mercado Comum & GMC & 62 & $28,05 \%$ & - \\
\hline $\begin{array}{l}\text { Fundo para a Convergência Estrutural do } \\
\text { Mercosul }\end{array}$ & FOCEM & 27 & $12,21 \%$ & - \\
\hline Foro de Consulta e Concertação Política & FCCP & 34 & $15,38 \%$ & $\begin{array}{l}3 \text { atos em conjunto } \\
\text { com a RME; } 4 \text { atos em } \\
\text { conjunto com a RMI }\end{array}$ \\
\hline Parlamento do Mercosul & Parlasul & 02 & $0,90 \%$ & - \\
\hline $\begin{array}{l}\text { Grupo de Alto Nível Estratégia Mercosul de } \\
\text { Crescimento do Emprego }\end{array}$ & GANEMPLE & 01 & $0,45 \%$ & - \\
\hline Grupo de Serviços & GS & 03 & $1,35 \%$ & - \\
\hline Grupo de Relacionamento Externo & GRELEX & 1 & $0,45 \%$ & - \\
\hline Reunião Especializada de Agricultura Familiar & REAF & 02 & $0,90 \%$ & - \\
\hline Grupo do Instituto Social do Mercosul & GISM & 01 & $0,45 \%$ & - \\
\hline $\begin{array}{l}\text { Foro Consultivo de Municípios, Estados Federa- } \\
\text { dos, Províncias e Departamentos do Mercosul }\end{array}$ & FCCR & 01 & $0,45 \%$ & - \\
\hline Comissão de Comércio do Mercosul & $\mathrm{CCM}$ & 08 & $3,61 \%$ & - \\
\hline Reunião Especializada de Ciência e Tecnologia & RECyT & 01 & $0,45 \%$ & - \\
\hline $\begin{array}{l}\text { Comissão de Representantes Permanentes do } \\
\text { Mercosul }\end{array}$ & CRPM & 07 & $3,16 \%$ & - \\
\hline $\begin{array}{l}\text { Reunião de Ministros e Autoridades de Desen- } \\
\text { volvimento Social }\end{array}$ & RMADS & 3 & $1,35 \%$ & - \\
\hline Reunião de Ministros de Educação & RME & 01 & $0,45 \%$ & - \\
\hline Reunião de Ministros de Interior & RMI & 02 & $0,90 \%$ & - \\
\hline $\begin{array}{l}\text { Grupo Ad Hoc para a elaboração da Integração } \\
\text { Produtiva do Mercosul }\end{array}$ & GAHIP & 2 & $0,90 \%$ & - \\
\hline Observatório da democracia do Mercosul & ODM & 1 & $0,45 \%$ & - \\
\hline $\begin{array}{l}\text { Grupo de Alto Nível para a Reforma Institucio- } \\
\text { nal do Mercosul }\end{array}$ & GANRI & 2 & $0,90 \%$ & - \\
\hline Total & & 221 & & \\
\hline
\end{tabular}

Fonte: As autoras, com base em dados coletados na página eletrônica oficial da Secretaria do Mercosul.

pelos governos dos Estados Partes, dentre os quais devem constar necessariamente representantes dos Ministérios das Relações Exteriores e da Economia e dos Bancos Centrais. Por fim, o FCCP, órgão auxiliar do CMC, é integrado por altos funcionários dos Ministérios de Relações Exteriores dos Estados Partes do Mercosul. Em suma, são as mesmas instituições dos Executivos nacionais que enviam $66 \%$ dos atos aprovados no CMC. A porcentagem 
pode ser maior, se forem considerados outros órgãos cujos membros também pertencem a órgãos vinculados aos poderes executivos.

Os dados analisados demonstram a dificuldade encontrada pelas instâncias regionais em se sobressaírem numa organização intergovernamental. Por meio da análise das decisões do CMC, percebe-se que elas são elaboradas quase que exclusivamente pelos Executivos nacionais, que geralmente têm menos interesse em aprovar medidas que acelerem o processo de integração. A influência de outros atores, onde se incluem os parlamentares, é bastante limitada. Essa concentração faz com que muitos órgãos do Mercosul produzam atos que não repercutem concretamente nas instâncias superiores, que ainda detêm, sem ameaças concretas, o monopólio da agenda do bloco.

\section{Conclusões}

Desde o final da década de 1990, o Mercosul tem passado por sucessivas crises econômicas e políticas. Recentemente, a queda do governo Lugo no Paraguai confirmou o reiterado descumprimento dos tratados assinados e os limites do diálogo político entre os sócios. O Parlasul não foge a esse quadro. Criada em um momento de revitalização política da integração, a assembleia conferiu um novo fôlego ao bloco ao constituir-se em uma arena suplementar de debate político, incluindo parlamentares e atores da sociedade civil. No entanto, ela não tem conseguido ultrapassar os limites burocráticos estabelecidos pelos órgãos executivos e encontra-se em situação de paralisia institucional desde o início de 2011. Em 2012, os parlamentares surpreendentemente não demonstraram maior capacidade política do que as diplomacias na gestão da crise paraguaia e, desmobilizados, não puderam aproveitar o momento para um relance das atividades do Parlasul. A situação de interrupção das sessões plenárias persiste em 2013 e 2014, apesar dos debates nas câmaras nacionais sobre as propostas de sufrágio universal.

Essa situação reflete-se na continuidade do domínio da agenda do Mercosul pelos poderes executivos. As decisões sobre a formulação e implementação de políticas regionais ficam, assim, restritas a um dos poderes do Estado, carecendo de debate público e legitimidade democrática. A internalização dos acordos nos congressos nacionais confere apenas uma impressão de legitimidade, tendo em vista que aos congressistas é facultado exclusivamente aprovar ou rejeitar propostas fechadas negociadas pelas diplomacias. Essas limitações procedimentais dificultam a própria construção da noção de bens públicos regionais (Botto 2011), tendo em vista que não há compartilhamento de informações ou preocupação com a formação de amplos consensos sociais a respeito dos conteúdos que devem ser ou não incluídos na agenda do bloco.

Ressalte-se que o comportamento dos parlamentares do Mercosul - que, em geral, não reivindicam expressamente maiores competências para o parlamento regional - é uma estratégia racional. Considerando que sua base política é nacional, não há incentivos para buscar mais competências no espaço regional. Essa lógica pode ser alterada com as eleições diretas, já que os mandatos dos parlamentares estariam vinculados ao parlamento regional, o que geraria incentivos para a adoção de uma postura mais assertiva. É importante também frisar que o artigo analisou a parcela das funções legislativas efetivamente implementadas pelos parlamentares. No entanto, uma parte significativa de seu potencial não vem sendo aproveitado: projetos e anteprojetos de lei são muito pouco numerosos, assim como foram pouco exploradas as funções vinculadas a orçamento e controle. Essa dificuldade em concretizar as funções já era prevista desde o início do órgão: 


\author{
${ }^{10}$ Entrevista da autora com \\ um assessor parlamentar \\ argentino em Montevideo, \\ março de 2009.
}

"Otro desafío importante es bajar a tierra las atribuciones que tiene el Protocolo. El Protocolo tiene muchas atribuciones, algunas de las cuales requieren un desarrollo normativo, y otras que requieren un desarrollo "en la realidad", así que el Parlamento desarrolle esas competencias. Si quedan en el Protocolo, pueden ser buenas competencias, pero están vacías de ejecución práctica. El tema es que el Parlamento tiene que implementarlas y utilizarlas directamente." 10 .

Analisando o caso da relação entre o CMC e o Parlasul, o trabalho demonstrou que os mecanismos de reação negativa mantêm-se no bloco, conferindo suporte às ações dos órgãos executivos. $\mathrm{O} C \mathrm{CMC}$, na maioria das vezes, não dá seguimento às recomendações enviadas pelo Parlasul. Os poderes executivos tentam, por meio da negligência para com os temas que preocupam os parlamentares, manter o controle da agenda decisória e evitar que um novo monopólio político, capitaneado por atores ligados ao Parlasul, forme-se no seio do bloco. Por outro lado, o Parlasul não tem conseguido explorar de modo eficaz seus instrumentos legislativos e sua capacidade de pressão política. O Parlasul não tem sido capaz de inserir temas na agenda decisória do Mercosul, assim como o próprio Parlamento segue relativamente impermeável às principais discussões que têm lugar no CMC. Com a votação de recomendações de baixo impacto econômico e social e a falta de apoio técnico para opinar sistematicamente sobre os assuntos centrais das reuniões do CMC, os parlamentares perdem oportunidades de erigir mecanismos de reação positiva que poderiam trazer aos cidadãos uma nova perspectiva sobre os problemas regionais.

Essa nova perspectiva está relacionada à conformação de um novo grupo político - também entendido como coalizão militante (Sabatier 1988), com ou sem apoio de comunidades epistêmicas (Haas 1992) - que tenha condições de atrair a atenção pública e seu apoio para os princípios que defende. Assim, mesmo minoritário, esse novo grupo poderia desafiar o monopólio constituído devido aos efeitos positivos vinculados a seus valores e propostas. O Parlasul pode ter esse alcance caso consiga organizar-se institucionalmente para formular e difundir propostas a respeito de temas sensíveis para a região ou relacionadas a assuntos para os quais as ações do CMC não são consideradas satisfatórias. Conjunturalmente, esse quadro depende de eleições diretas para o cargo de deputado do Mercosul e da contratação, por meio de concurso público internacional, de funcionários tecnicamente qualificados para trabalhar no Parlasul. Estruturalmente, as características do presidencialismo de coalizão dos países do Cone Sul dificultam uma atuação afirmativa dos parlamentares face aos poderes executivos. Essas condições vinculam definitivamente a eficácia da dimensão parlamentar do Mercosul ao ritmo do processo de consolidação democrática em cursos nos Estados da região.

Clarissa Franzoi Dri (clarissa.dri@ufsc.br) é Doutora em Ciência Política pela Universidade de Bordeaux (França) e Professora do Departamento de Economia e Relações Internacionais da Universidade Federal de Santa Catarina (UFSC). Vínculo institucional: Universidade Federal de Santa Catarina, Florianópolis, SC, Brasil

Maria Eduarda Paiva (mariaeduardapaiva@gmail.com) é Mestre em Ciência Política pela Universidade Federal de Pernambuco (UFPE) e analista de políticas sociais no Ministério do Desenvolvimento Social e Combate à Fome. Vínculo institucional: Ministério do Desenvolvimento Social e Combate à Fome, Brasília, DF, Brasil.

\section{Referências}

Baumgartner, F. \& Jones, B., 1991. Agenda Dynamics and Policy Subsystems. The Journal of Politics, 53(4), pp.1044-1074. DOI: $10.2307 / 2131866$

2009. Agendas and Instability in American Politics. 2. ed. Chicago: University of Chicago Press.

2002. Positive and Negative Feedback in Politics. In F. Baumgartner \& B. Jones, eds. Policy Dynamics. Chicago: University of Chicago Press.

Botto, M., 2011. Qué nos enseñan los 20 años del Mercosur? Nueva Sociedad, 232, pp.17-25. 
Costa, O. \& Saint Martin, F., 2009. Le Parlement européen. Paris: La Documentation Française.

Dri, C., 2009. At What Point Does a Legislature Become Institutionalized? The Mercosur Parliament's Path. Brazilian Political Science Review, 3(2), pp.60-97.

Haas, P., 1992. Introduction: Epistemic communities and international policy. International Organization, 46(1), pp. 1-35. DOI: $10.1017 / \mathrm{S} 0020818300001442$

Kingdon, J., 1984. Agendas, Alternatives, and Public Policies. Boston: Little, Brown and Co.

Medeiros, M.; Paiva, M.E. \& Lamenha, M. 2012. Legitimidade, representação e tomada de decisão: o Parlamento Europeu e o Parlasul em perspectiva comparada. Revista Brasileira de Política Internacional, 55(1), pp.154-173. DOI: 10.1590/S0034-73292012000100009

Ravinet, P., 2004. Fenêtre d'opportunité. In L. Boussaguet; S. Jacquot \& P. Ravinet, P., eds. Dictionnaire des politiques publiques. Paris: Les Presses de Sciences Po.

Sabatier, P., 1988. An Advocacy Coalition Framework of Policy Change and the role of Policy-Oriented Learning therein. Policy Sciences, 21(2-3), pp.129-168. DOI: 10.1007/BF00136406 , ed., 1999. Theories of the Policy Process. Oxford: Westview Press.

True, J.; Jones, B. \& Baumgartner, F. 1999. Punctuated-Equilibrium Theory: Explaining Stability and Change in American Policymaking. In P. Sabatier, ed. Theories of the Policy Process. Oxford: Westview Press.

\begin{abstract}
The participation of the Mercosur Parliament (Parlasur) in the regional decision-making is legally restricted. Parlasur's attributions are limited and include, for instance, the elaboration of bills and recommendations to be sent to superior organs. This paper analyses if and in which manner Parlasur uses these competences to influence regional decisions. We argue that there are formal and informal mechanisms which, even limited, would allow Parlasur to intervene in the debates which take place within decisional organs. In order to evaluate wheter agenda-setting is a parliamentary power in Mercosur and if it is effective, we proceed to a quali-quantitative analysis of the recommendations sent by Parlasur to the Common Market Council (CMC). After establishing a typology of the recommendations sent by Parlasur to CMC between 2007 and 2010, we evaluate CMC's response rate (quantitatively) and CMC's manifestations on Parlasur's positions (qualitatively). We also compare CMC's and Parlasur's agendas in order to identify eventual superposition or coincidence of issues. Conclusions point out to a systematic lack of consideration of parliamentary initiatives which aim at keeping the monopole of Executive Powers in the regional arena. CMC only "acknowledges receipt" of the great majority of recommendations sent by Parlasur and has approved less than 5\% of them. There is a very weak match of issues between the agendas of both organs, showing that topics discussed by Parlasur are rarely transformed into Mercosur rules. Results confirm the lack of influence of actors other than Executive Powers in the decision-making of Mercosur. The article points out the mechanisms that have been used to prevent the legislative branch to be considered in regional decisions. If members of Parliament are aware of them, they may press executive organs to formulate better responses, which may engender a different role for parliaments in foreign policy matters.
\end{abstract}

KEYWORDS: Mercosur; legislative power; Punctuated Equilibrium Theory; agenda-setting; regional democracy.

This is an Open Access article distributed under the terms of the Creative Commons Attribution Non-Commercial License which permits unrestricted non-commercial use, distribution, and reproduction in any medium provided the original work is properly cited. 